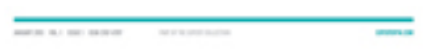

\title{
OPPETION
}

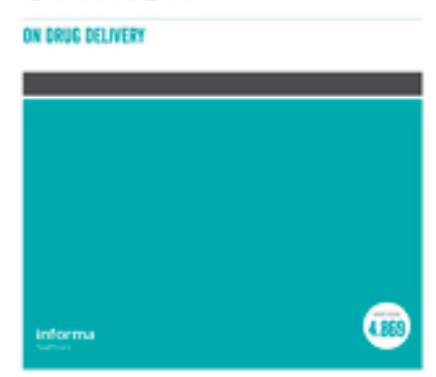

Please download and read the instructions before proceeding to the peer review

\section{Liposomes: A promising carrier for respiratory syncytial virus therapeutics}

\begin{tabular}{|r|l|}
\hline Journal: & Expert Opinion on Drug Delivery \\
\hline Manuscript ID & EODD-2019-ST-0117.R1 \\
\hline Manuscript Type: & Review \\
\hline Keywords: & RSV, Liposome, Lipids, Peptides, small molecules, drugs \\
\hline \multicolumn{2}{l}{} \\
\end{tabular}

\section{SCHOLARONE Manuscripts}




\title{
Liposomes: A promising carrier for respiratory syncytial virus therapeutics
}

\author{
Sameer Joshi ${ }^{1, *}$, Swapnil Bawage ${ }^{2}$, Pooja Tiwari², Daniel Kirby ${ }^{3}$, Yvonne Perrie ${ }^{4}$, Vida \\ Dennis ${ }^{1}$, Shree R Singh1
}

1. Alabama State University, Montgomery, AL, USA.

2. Wallace H. Coulter Department of Biomedical Engineering, Georgia Institute of Technology and Emory University, Atlanta, GA 30332, USA.

3. Aston Pharmacy School, School of Life and Health Sciences, Aston University, Birmingham B4 7ET, UK.

4. Strathclyde Institute of Pharmacy and Biomedical Sciences, University of Strathclyde, 161 Cathedral Street, Glasgow G4 ORE, UK.

\footnotetext{
${ }^{*}$ Correspondence

Sameer Joshi

Alabama State University Ringgold standard institution, Montgomery 36104-5732, USA

Email: sjoshi@alasu.edu
} 


\begin{abstract}
Introduction: Human respiratory syncytial virus (RSV) is a common respiratory virus that causes severe lower respiratory tract infection in infants, children and aged adults. Currently, there is no active prophylaxis present in the market for RSV infection; however, there are over a dozen compounds being tested in the laboratory as well as clinical trials. To increase the efficiency and safety of these therapeutics, there is a need for delivery vehicles.

Areas covered: Liposomes can be used for delivering anti-RSV agents with the advantage of modulating and eliciting the desired adjuvant effect by the different combination of lipids. This review discusses the promising application of liposome for anti-RSV therapeutics.

Expert opinion: Liposomes are attracting attention for delivery of pulmonary therapeutics, since they offer compatibility for delivering drugs, vaccines and other therapeutic molecules. Variation in liposome size and composition gives flexibility for the amount and number of deliverables, whilst targeted delivery with the capability for immunomodulation makes liposomes a promising candidate for RSV therapeutic applications.
\end{abstract}

Keywords: RSV, liposomes, lipids, peptides, small molecules, drugs 


\section{Article highlights}

- Currently, broad spectrum antiviral drug ribavirin and palivizumab (monoclonal antibody) are solacing measures against RSV infection. However, there is no effective prophylaxis or treatment available for RSV infection.

- There are several potential therapeutic candidates in pre-clinical and clinical trials and their efficacy can be enhanced by using effective delivery vehicles.

- There are many drug delivery systems available; however, liposomes are the most successful drug delivery vehicles in the market. Application of liposomes for RSV drug delivery is largely unexplored.

- Liposomes offer versatile ways of loading polar and non-polar therapeutic candidates. Modulating liposome synthesis chemistry not only allows controlled release but also targeted delivery of cargo. These characteristics of liposomes are desirable for targeting lung pathogen like RSV.

- Liposomes may stimulate immune system and can be a favorable when delivering vaccines. Modulating pharmacokinetics and pharmacodynamics events of a drug could be achieved by liposomal drug delivery.

- An overlapping perspective of RSV pathology, therapeutics and liposome engineering is crucial in development of RSV vaccine and drugs and needs to extrapolate this multidisciplinary approach.

\section{Introduction}

An attentive basis of the respiratory tract infections such as bronchitis and pneumonia is generally respiratory syncytial virus (RSV). Worldwide, RSV is the leading cause of acute lower respiratory tract (LRTI) infections [1]. It is a negative sense ssRNA virus, which belongs to the order Mononegavirales and Pneumoviridae family. The transmission of RSV is primarily through air droplets from infected individuals or indirectly through fomites [2]. RSV infection is conspicuous during winter on populations including all age groups from fetus and infants [3] to older adults [4]. For the year 2015, 
the globally estimated incidents of RSV associated LTRI in children below 5 years was about 33.1 million, which resulted in 3.2 million hospitalizations and 59600 in-hospital mortalities [5].

Moreover, $45 \%$ of hospitalization and in-hospital deaths of children below the age of 6 months is caused by RSV associated LTRI, with RSV frequently the basis of respiratory tract infections such as bronchitis and pneumonia [5]. In the USA, thousands of hospitalizations and over 2 million hospital visits were recorded between the years 2014-2017 for RSV infections.

Initially, the RSV invades nasopharyngeal epithelium causing mild upper respiratory tract infection (URTI) and may progress to potentially precarious LRTI by intracellular transmission, where most of RSV replication is dominant [6]. The infection causes severe bronchitis and respiratory discomfort like apnea. Since the natural infection is not capable of educing life-long immunity, the individuals affected are prone to repeated RSV infection [7]. Furthermore, there is currently no vaccine available for prophylaxis and, whilst the broad-spectrum antiviral drug ribavirin is used for treatment, its clinical efficacy is variable. Although Palivizumab - a humanized monoclonal antibody against RSV - represents a helpful option to be prescribed for high-risk individuals, this comes at a high cost [8]. As such, the treatment for RSV is generally limited to supportive measures, including drugs to reduce the inflammation and antibiotics to reduce the risk of bacterial infections.

Consequently, the need for prophylaxis and an effective treatment regime against RSV is imperative. Currently, there are approximately 20 anti-viral drugs, and over 12 vaccines are in clinical trials [9]. A common limitation in anti-RSV therapeutic product development is that therapeutics often suffer from early degradation or body clearance and may cause undesired effects such as toxicity. These issues can be resolved by encapsulating the therapeutic agents within nanocarriers, which protects the therapeutic agent from degradation and offers advantages of controlled release and effective delivery $[10,11,12]$. Several materials for nano-deliverables like chitosan, poly (lacticco-glycolic) acid, polylactic acid and poly (2-hydroxyethyl methacrylate) [13, 14] have been explored against RSV. However, liposomes, which are widely used for drug 
delivery and have also been approved and marketed for human use, are yet to be fully exploited for RSV [15]. The potential of liposomes as a carrier of active therapeutic agents was described decades ago $[16,17,18]$, while liposomes have attracted much attention for their ability to carry antigens as well as immunomodulators [19]. They can express adjuvant action by enhanced antigen delivery or inducing innate immune responses [20]. Liposomes have been used widely for various diseases and disorders; some are in clinical trials, while others have made the market [21]. This indicates the significance and promise of liposomes for drug delivery. Here, we present the relevance and promise of liposome-based nanoparticulate systems for vaccines and drugs against RSV.

\subsection{Infection of the respiratory tract by RSV}

\subsubsection{RSV life cycle}

RSV has a single-stranded 15,222 nt long RNA genome encoding 11 proteins including 2-non-structural proteins (NS-1 and NA-2), 3-surface proteins (glycoprotein-G, fusion protein- $\mathrm{F}$, and small hydrophobic protein- $\mathrm{SH}$ ), two overlapping frames of $\mathrm{M} 2$ mRNA produce 2 distinct matrix proteins (M-1 and M-2) and 4 other structural proteins (matrix protein-M, nucleocapsid-N, phosphoprotein-P and large protein-L) (Figure 1) [6, 22]. The viral envelope of the RSV has three membrane proteins, namely $G, F$, and $M$ (Figure 1). A successful RSV life cycle is an interplay of viral and cellular components that eventually favors viral replication and establishment of infection (Figure 2). RSV infection initiates with the attachment of viral $G$ protein to cellular proteins like CX3CR1 [23], surfactant protein A [24], or annexin II [25]. The entry of virion particle into the cell is determined by the critical step of virion and cell membrane fusion carried out by RSV $F$ protein. The nucleolin protein acts as a receptor for RSV F protein [26]. The trimeric $F$ protein changes conformation, facilitated by six-helix bundles, to fuse the virus and cell membrane [27]. The $F$ and $G$ proteins are conserved and candidates for vaccine and drug development. The viral disassembly and release of RNA genome facilitates transcription of mRNA and translation of proteins; on the other hand, the anti-genome enables more viral RNA genome copies to be made. The viral proteins then assemble 
along with the genome in the cytoplasm or cell membrane to release new viral particles or filaments $[28,29]$.

\subsection{Therapeutics for RSV}

\subsubsection{Current research on prophylaxis and treatment for RSV infection}

Considering published outcomes related to treatment, as well as the impact of RSV on global healthcare, a promising treatment or vaccine development remains a priority. The viral replication by itself is not as harmful as the inflammation due to the infection; the infection leads to a complex immune response and, therefore, developing vaccines has been a challenge. The formalin-inactivated vaccine was launched in the 1960s and later withdrawn due to poor immunogenic response as well as atypical $T_{H_{2}} 2-$ type response, increasing chances of reinfection with similar or deadly infections [30]. Attaining the balance between immunity and viral attenuation is very difficult. Therefore, developing a live attenuated vaccine for RSV is the primary goal for many researchers [31]. Clinical trials have demonstrated that intranasal administration of the vaccine restricts viral replication in infants after second dose [32]. There is more than half a dozen live attenuated vaccines under trial [32, 33, 34]. A live-attenuated vaccine cpts248/404 was administered intranasally, tested in phase 1 trials [33]. In this trial, a total

of 114 children, out of which few were <2-year-old infants were targeted. Unfortunately, the vaccine cpts-248/404 was found infectious and was mostly immunogenic for the children above the age of 6 months [33].

The genome of the RSV is comprised of immunogenic proteins and this creates scope to develop DNA, subunit and other nano vaccines [13]. These vaccines can be designed as carrier-based vaccines, through the use of nanoparticulate systems, such as liposomes, that can express adjuvant action by enhanced antigen delivery or inducing innate immune responses [20].

On the other hand, for the treatment of RSV infection, the only approved product against RSV infection is 'Palivizumab,' which is a humanized monoclonal antibody targeting the RSV $[35,36]$. The first line treatment of RSV infection is the use of 
bronchodilators, such as $\alpha$ and $\beta$ adrenergic agonist [6]. For pediatrics, since corticosteroids are not approved for treating RSV infected individuals less than 1 year old due to safety concerns [37], the use of vaporub and non-aspirin formulations, such as paracetamol, are the treatments of choice prior to clinical attention. Of the very few options available for the treatment of RSV, ribavirin, a broad spectrum antiviral drug, is used, although this too comes with limitations and drawbacks such as mutagenicity, teratogenicity as well as carcinogenicity $[13,38]$; despite several concept studies claiming effectiveness of ribavirin in significantly reducing the RSV load and minimizing disease severity, the disadvantages of mutagenicity, teratogenicity and carcinogenicity subsequently resulted in FDA denial [39]. However, along with just a couple of L-protein inhibitors, there are Over 20 candidates that are currently under clinical and preclinical research have been found targeting RSV fusion protein (Table-1) [40] and liposomes has been considered as delivery vehicle for few of these candidates that are are undergoing in-vitro studies [41, 42, 43]; very recent research demonstrated that liposomes can become a carrier for the anti-RSV fusion peptide [15].

Similarly, and mainly for the peptide, the liposomal delivery system could play a vital role in RSV vaccine design. A benzimidazole derivative JNJ-2408068 was reported to be a potent inhibitor of RSV, but due to the limited extrapulmonary distribution, the development was halted $[44,45]$. In such cases, to elicit the immune response the candidates such as adjuvants could ease the distribution and provide long-lasting immunity [46]. One of the adjuvants based RSV F vaccine is under phase 3 clinical trials $[47,48]$.

However, one of the challenges in using liposomes as a delivery vehicle is overcoming the strong hydration forces acting on the bilayer when the bilayer comes at a distance less than $20 \AA$ [49]. Hence, the fusion proteins, due to their characteristics, have become attractive to the researchers as they can be vital in one or all steps of delivery or fusion process. The possibility of using lipid in RSV vaccine design was patented in the late 90s [50]. The activity of the vaccine and vaccine composition can be enhanced using modulators like adjuvants, simple organic molecules and mechanical means, such as heating antigen [51]. Liposomes can be used as adjuvants [10, 19, 52]. Designing a protein based liposomal adjuvant vaccine could be an approach to attain 
maximum efficacy and low toxicity [53]. Based on the establishments in the proteinbased liposomal adjuvant vaccine, protein and peptides ranging from $0.1 \mu \mathrm{g}$ to $100 \mu \mathrm{g}$ can be used in the vaccine designing; whereas the use of an excess carrier is recommended to achieve maximum payload [50]. 
Table 1 Research in prophylaxis or treatment against RSV infection.

\begin{tabular}{|c|c|c|c|c|}
\hline Drug & Form & Target protein & Stage of testing & References \\
\hline \multicolumn{5}{|l|}{ FDA Approved } \\
\hline Palivizumab & Monoclonal antibody & $\mathrm{F}$ & FDA approved & {$[54,55]$} \\
\hline \multicolumn{5}{|l|}{ Clinical Trials } \\
\hline Motavizumab & Monoclonal antibody & $\mathrm{F}$ & License application is withdrawn from FDA & {$[56,57]$} \\
\hline REGN2222 & Monoclonal antibody & $\mathrm{F}$ & Phase 3 & {$[58]$} \\
\hline GS-5806 & Fusion Inhibitor & $\mathrm{F}$ & Phase 2 (completed) & {$[59,60]$} \\
\hline JNJ-2408068 & Fusion Inhibitor & $\mathrm{F}$ & Phase $2 a$ & [61] \\
\hline JNJ-678 & Fusion Inhibitor & $\mathrm{F}$ & Phase $2 a$ & [62] \\
\hline RV-521 & Fusion Inhibitor & $\mathrm{F}$ & Phase 2a & {$[63,64]$} \\
\hline AK-0529 & Fusion Inhibitor & $\mathrm{F}$ & Phase 2 & {$[63,65]$} \\
\hline BTA-C585 & Fusion Inhibitor & $\mathrm{F}$ & Clinical studies & {$[66,67]$} \\
\hline VP-14637 & Fusion Inhibitor & $\mathrm{F}$ & Phase 1 & {$[61,68]$} \\
\hline BTA9881 & Fusion Inhibitor & $\mathrm{F}$ & Phase 1 & {$[67,69,70]$} \\
\hline PC786 & L-Protein Inhibitor & $\mathrm{L}$ & Phase 2 & {$[58,71]$} \\
\hline AZ-27 & L-Protein Inhibitor & $\mathrm{L}$ & Phase 2 & [72] \\
\hline \multicolumn{5}{|l|}{ In-Vivo Studies } \\
\hline RFI-614 & Fusion Inhibitor & $\mathrm{F}$ & African green monkeys, BALB/c mice, Cotton rats & [73] \\
\hline TMC-353121 & Fusion Inhibitor & $\mathrm{F}$ & BALB/c mice, African Green Monkeys & {$[70,74,75]$} \\
\hline RFI-641 & Fusion Inhibitor & $\mathrm{F}$ & African green monkeys, Cotton rats & {$[73,76,77]$} \\
\hline CL387626 & Fusion Inhibitor & $\mathrm{F}$ & Cotton rats & {$[78,79]$} \\
\hline \multicolumn{5}{|l|}{ In-Vitro Studies } \\
\hline HRA-30a & Fusion Inhibitor & $\mathrm{F}$ & HEp-2 & [80] \\
\hline HR121 & Fusion Inhibitor & $\mathrm{F}$ & HEp-2 & [81] \\
\hline HR212 & Fusion Inhibitor & $\mathrm{F}$ & HEp-2 & [81] \\
\hline F478 -516 & Fusion Inhibitor & $\mathrm{F}$ & HEp-2 & [82] \\
\hline RF-482 & Fusion Inhibitor & $\mathrm{F}$ & HEp-2 & {$[15,83]$} \\
\hline RF-491 & Fusion Inhibitor & $\mathrm{F}$ & HEp-2 & [83] \\
\hline BMS-433771 & Fusion Inhibitor & $\mathrm{F}$ & HEp-2 & {$[66,84]$} \\
\hline
\end{tabular}




\subsection{Current non-liposomal delivery methods for RSV}

Different biomaterials and synthetic polymer-based cargo delivery systems have been used for RSV therapeutics. Drug and vaccine delivery for RSV using these nonliposomal delivery methods have made attempts to improve the balance of delivery of cargo and safely elicit an immune response or inhibit the virus. The approach of using cargo itself is the delivery particulate system; a popular example of this is the virus-like particles (VLP), which have garnered tremendous interest among RSV vaccine development $[85,86,87,88,89]$. Although this is not directly in the scope of this review, it is worth mentioning. Novel drug delivery systems (NDDS) have given new insight into the medical treatments due to their unique abilities to enhance therapeutic effect and reduce toxicity [90]. Size of the particles is responsible for the permeability, retention and immune response [91]. Hence, the nanoparticulate delivery systems are preferred by many researchers around the globe to achieve enhanced permeability and retention (EPR).

These delivery methods can be broadly divided into metallic and non-metallic nanoparticles. A novel approach to inhibit RSV was the use of gold nanoparticles (GNPs). These GNPs can be functionalized with nucleic acid, antibodies, drugs, as well as with peptides, and these functionalized GNPs can then be applied in diagnosis or treatment [92]. Similar to the gold nanoparticles but different in shape are the gold nanorods. Gold nanorods can accumulate into the extracellular matrix (ECM), taken up by phagocytosis and trigger TLR signaling pathway [93]. After gold, silver is the metal that has been studied extensively by researchers for a variety of purposes. Silver nanoparticles conjugated with recombinant RSV fusion protein has also been reported to bring anti-RSV effect [94].

There are a variety of non-metallic materials that have been considered to produce particulate delivery systems. Cationic particles of chitosan are biocompatible, biodegradable and a proven vaccine carrier [13]. Enhanced delivery of RSV DNA vaccine was observed using chitosan nanoparticles when compared to naked DNA [95]. Composite chitosan gene delivery systems can be produced with the addition of polymers such as poly (2-hydroxyethyl methacrylate) [92] and alginate [96]. PLGA 
nanoparticles have also been used as a carrier of F-protein delivered intranasally and intra-gastrically [97]. Compared to the chitosan and PLGA particulate system, the silicabased particulate system is less explored. Mesoporous silica is shown to have adjuvantlike properties [98], low toxicity [98, 99] and can be given orally [98]. Lutz and colleagues have recently reported 'nanogels' as a biodegradable carrier of covalently linked imidazoquinoline (IMDQ) TLR7/8 agonist to treat RSV [100]. A carrier similar to the liposome used in the treatment of RSV is 'niosome.' Niosomal structures resemble liposomes, but are vesicles of non-ionic surfactants. Asthana and colleagues have used niosomes to encapsulate clarithromycin, which is a broad spectrum, second-generation macrolide antibiotic used in the treatment of respiratory tract infections [101]. Another type of particulate system called 'dendrimer', a structure of repeatedly branched molecules, has also been discovered to be beneficial in the treatment of RSV infection [102]. Similar to dendrimers, micro and nano particles can be prepared from multilayered amino acids; these particles can encapsulate anti-RSV proteins in their hollow-shell structure [103].

\subsection{Why liposomes for RSV?}

Liposomes were first discovered by Bangham and colleagues and described as swollen phospholipid systems [104]. The application of liposomes in drug and vaccine delivery was first proposed by Gregoriadis [52]. Liposomes are composed of lipids, that when forced into an aqueous environment, align to form bilayered vesicles, which can be single or multi-lamellar and can be prepared in the range of approximately $50 \mathrm{~nm}$ to several microns (Figure 3). Liposomes for drug delivery have existed as marketed products for many years; brands like Ambisome $\AA$, DepoDur ${ }^{\mathrm{TM}}$, Depocyt $\AA$, Doxil $(\AA$, Mepact $\circledast$ are a few examples. Now, liposomes are established suprastructures in vaccination [105]; Epaxal $\circledast$ and Inflexal® $\vee$ for hepatitis A virus and Influenza virus [21], respectively, demonstrate the relevance of liposomes for therapeutics against viral pathogens. In spite of the establishment of liposomes as vaccine delivery systems, studies of promising liposomal vaccines against RSV are still under research. 
The history of using liposomes for RSV vaccine systems has been fascinating; in the early 90 s, Connor and colleagues described that the recombinant vaccine with $\mathrm{M}$ protein could challenge RSV by inducing CD8+T cells mediated immune response; whereas, the $G$ and $F$ - protein vaccine challenges RSV through the immune response caused by antibodies [106]. There are random possibilities in the case of $G$ and $F$ protein vaccines; one of which is that the observed RSV resistance could have been through the mucosal IgA antibodies, whereas the other could have been an unknown factor assisting these antibodies to deplete the CD4+ or CD8+ T cells. However; in contrast to this, it was reported that the M-protein vaccine challenging RSV did not induce the serum neutralizing antibodies and purely revoked by depletion of CD8+ T cells. Apparently, based on this, a soluble G-protein fragment of the RSV was encapsulated in dioleoyl phosphatidylcholine (DOPC) liposomes to induce immunization against the RSV [42]. In the extensive research by Huang and colleagues, they have found that a fusion product of soluble fragment of the G-protein of RSV and thioredoxin protein from the Deinococcus radiodurans bacterium can be encapsulated into the liposomes made of the lipid DOPC alone or in combination with the lipids originated from the radiation-resistant bacterium, Deinococcus radiodurans, which are unique in nature and are capable of inhibiting growth of RSV [43].

Moreover, in their research, they have found that the liposomes made up of the lipid DOPC in combination with lipid 7 ( $\alpha$-Galactosylphophatidylglyceroylalkalamine) isolated from the total lipids of Deinococcus radiodurans bacterium and having the Gprotein and thioredoxin protein fusion product was prominently effective against RSV. It was reported that the RSV has no cytotoxic T cells epitope [106]; therefore, the inhibitory effect of G-protein of RSV and thioredoxin protein fusion product is due to liposomes which were taken up by antigen presenting cells. This suggests that the liposomes not only can become a carrier for the vaccine but also can exert an adjuvant effect.

Alveolar macrophages have a vital role in the prevention of RSV infection as they produce an innate immune response facilitated by pro-inflammatory cytokines, for example tumor necrosis factor (TNF) [107]. During the last decade, an exciting finding came into focus, which described encapsulation of RSV antigen inside liposomes and 
the prompt incursion of the neutrophils. However, the influx of neutrophils was doubtful and possibly due to reasons such as to clear the debris of dying macrophages or in response to the macrophages engulfing the liposomes [108, 109]. However, depletion of macrophages was markedly observed post-administration of liposomes encapsulated with viral antigen [108]. A possible reason could be that the alveolar macrophages differentiate in presence of surfactant and lipids are surface active agents [110].Geall and colleagues had designed self-amplifying RNA vaccine using the lipid nanoparticles, which also can be called liposomes [111]. Subcutaneous (S.C.) administration of these lipid nanoparticles produce an innate immune response, but the reason for using low surface charged lipids seems unclear. However, use of liposomes can stabilize the RNA for long-term and can eliminate the risk of new infections caused by carrier-based vaccine $[111,112]$. This finding matches with the research by Lee and colleagues, where they had observed that liposomes could deplete the macrophages. Based on their results, the study seems promising, but their research also states that the pathological features of RSV in mice and human are different [112]. So, the benefit of doubt persists with this promising study in the quest of RSV vaccine research.

A recent discovery describes that the heparin octasaccharide decoy liposomes hold the potential of inhibiting cellular attachment of some pathogens, including RSV [113]. The research describes that the decoy receptors functionalized with the heparin sulfate bind to the pathogens and thereby the pathogen cannot further bind to susceptive cells. However, although the functionalized liposomes have inhibited the cellular attachment, they were not able to stop the replication of RSV through infected cells and syncytia formation. Moreover, heparin sulfate, due to its anticoagulant nature, may be an issue to be used as an anti-viral agent.

Research has also has come forward recently where the RSV small hydrophobic (SH) protein can be targeted by using an inhibitor known as 'pyronin B' [114]. Small hydrophobic protein is a small 64 -amino acid encoding peptide. Although the role of the small hydrophobic proteins in RSV infection is not well understood, Li and colleagues had found that the pyronin $B$ binds the small hydrophobic protein from the lipid face and not from the pore lumen. Binding in this region blocks the small hydrophobic protein channel and thereby inhibits the growth of the RSV [114]. Interestingly, the binding of 
pyronin B was concluded from a liposome-based assay, where the small hydrophobic protein was encapsulated into the liposomes, and the attachment of this protein was confirmed by nuclear magnetic resonance (NMR) spectroscopy. Here, it would have been interesting to see whether the pyronin $B$ encapsulated into the liposomes can exert some effect in comparison with the pyronin B alone.

Alternatively, liposomes can be designed to look like a virus and known as virosomes [115] and are virus without a genome. Inhibition of RSV infection was recently observed with the virosomes made of 1,2-dihexanoyl-sn-glycerol-3phosphocholine (DCPC), egg phosphatidylcholine (PC) and egg phosphatidylethanolamine (PE) were used to immunize the mice and challenged with live RSV [7, 115]. Kamphuis and colleagues have reported that immunization of mice with lipid made virosomes shown to have increased level of virus neutralizing IgG2a antibodies and IFN-y expression [7].

\subsection{Lipids used for RSV inhibition}

Approximately $90 \%$ of the pulmonary surfactant composition is lipids [116, 117]. In recent years, names of various lipids have appeared in the research for treating the RSV infection; for example, Numata and colleagues have mentioned that the inhibition of RSV is possible by thephosphoinositol (PI) surfactant lipid [117] and have classified phospholipids as major and minor; the PC is considered as the major, whereas the PI and PG are regarded as minor. In the same research, Numata and colleagues explain that the PI lipid stops the RSV spread by blocking the RSV to cell attachment and not by acting on virus directly; whereas, approximately $20 \%$ reduction in percentage plaque numbers was observed when treating RSV with PC lipid [117]. However, the mechanism of action of PG also involves blocking virus-cell attachment $[118,119]$ but the lipid PG is found to be less effective than PI [116, 117]. Referring to their research, it can be concluded that both major and minor lipids are capable of stoping RSV spread to an extent, although the mechanism of action is different.

In the past, researchers have mentioned the virucidal effect of glycerides and fatty acids against RSV $[120,121]$. Hilmarsson and colleagues have noted that, without 
changing they hydrophilic-lipophilic balance (HLB) value and merely changing the $\mathrm{pH}$ from neutral to acidic, the virucidal activity of the compound is increased [120].

Surprisingly, steroids and carotenoids are ineffective against RSV infection [122, 123], but other derived lipids, such as terpenoids, are being considered as potential anti-RSV agents [124].

Table 2 Lipids used for RSV inhibition and the proposed activity of the lipids towards RSV. (PC= Phosphatidylcholine, $\mathrm{PI}=$ Phosphatidylinositol, $\mathrm{PG}=$ Phosphatidylglycerol).

\begin{tabular}{|c|c|c|c|}
\hline \multicolumn{2}{|l|}{ Lipid } & Activity & Reference \\
\hline \multirow{3}{*}{ Simple Lipid } & $\mathrm{PC}$ & Virucidal & {$[15,117]$} \\
\hline & $\mathrm{PI}$ & $\begin{array}{l}\text { Blocks the virus-cell } \\
\text { attachment }\end{array}$ & [117] \\
\hline & PG & $\begin{array}{l}\text { Blocks the virus-cell } \\
\text { attachment }\end{array}$ & $\begin{array}{l}{[116,117,118,119,} \\
120]\end{array}$ \\
\hline \multirow{2}{*}{ Compound Lipid } & Fatty Acids & Virucidal & {$[120,121]$} \\
\hline & Glycerides & Virucidal & {$[120,121]$} \\
\hline Derived Lipid & Terpenoids & Virucidal & {$[124,125]$} \\
\hline
\end{tabular}

\subsection{Selection of lipids for liposomal formulation}

The formation of liposomes can be described as a two-step process; the first step is bilayer formation and the second is the closing of the bilayer to form liposomes. The transition temperature of lipids is responsible for their phase change, and lipids, when at temperatures above their transition temperature, will initially orientate into parallel alignment and form a sheet-like structure; subsequently, liposomes form by the bilayer sheet closing onto a vesicle structure to reduce tension [126].

Increasing the hydrophobic chain length of lipids increases their transition temperature. Transition temperature (Tc) plays a crucial role in the formation, as well as 
membrane fluidity of liposomes [127]. The lipid transition temperature is the temperature where the lipid changes its phase from an ordered solid state of lipid to disordered liquid crystalline state. In the ordered solid state, the hydrocarbon chains are extended and packed; whereas in the disordered state, the chains are randomly oriented.

In consideration of their application, the liposomal transition temperature is a key factor. Employing lipids with transition temperatures about body temperature $\left(>37^{\circ} \mathrm{C}\right)$ make lipid bilayers less prone to leakage and uptake by the MPS at physiological temperature [128]. On the other hand, liposomes with lower $\operatorname{Tc}\left(<37^{\circ} \mathrm{C}\right)$ are more susceptible to leakage at physiological temperature and may experience quick uptake by MPS or lose their original structure at that temperature $[129,130]$. The long saturated alkyl chains result in higher transition temperature, and this property is beneficial for drug retention in vivo. For example, DSPC shows better drug retention compared to 1,2-dipalmitoyl-sn-glycerol-3-phosphocholine (DPPC) [131]. Furthermore, the long saturated chains of DSPC increase the probability of high drug loading, especially for lipid soluble drugs [11, 12]. Although there are a variety of lipids that have been reported, the use of PC lipid can be seen prominently in the marketed formulations (Table 3). 
Table 3 Name, therapeutics and composition details of the marketed liposomal formulations. (HSPC= Hydro Soy PC, DSPG = 1,2-distearoyl-sn-glycero-3-phospho-(1'-rac-glycerol), EPC = L-a-Phosphatidylcholine (Egg, Chicken-60\%), DSPC = 1,2distearoyl-sn-glycero-3-phosphocholine, DPPC = 1,2-dipalmitoyl-sn-glycero-3-phosphocholine, DSPE = 1,2-Distearoyl-snglycero-3-phosphoethanolamine, EPG = L-a-phosphatidylglycerol (Egg, Chicken), DMPC = 1,2-dimyristoyl-sn-glycero-3phosphocholine, DOPC = 1,2-dioleoyl-sn-glycero-3-phosphocholine, DPPG = 1,2-dipalmitoyl-sn-glycero-3phosphoglycerol.)

\begin{tabular}{|c|c|c|c|}
\hline Product & Drug & Therapeutic use & Lipids \\
\hline Ambisome & Amphotericin B & Antifungal & HSPC, DSPG, cholesterol \\
\hline Myocet & Doxorubicin & Anti-cancer & EPC and cholesterol \\
\hline Doxil & Doxorubicin & Anti-cancer & HSPC, cholesterol and PEG 2000 \\
\hline Caelyx & Doxorubicin & Anti-cancer & HSPC, cholesterol and PEG 2000 \\
\hline LipoDox & Doxorubicin & Anti-cancer & DSPC, cholesterol , PEG 2000-DSPE \\
\hline Thermodox & Doxorubicin & Anti-cancer & DPPC, and PEG2000-DSPE \\
\hline DaunoXome & Daunorubicin & Anti-cancer & DSPC and cholesterol \\
\hline Marqibo & Vincristine & Anti-cancer & Egg sphingomylin and cholesterol \\
\hline Visudyne & Verteporfin & Macular degeneration & EPG, DMPC \\
\hline DepoCyt & Cytarabine & Anti-cancer & DOPC, DPPG and cholesterol \\
\hline DepoDur & Morphine sulfate & Opioid Analgesic & DOPC, DPPG, and cholesterol \\
\hline Arikace & Amikacin & Bacterial infections & DPPC and cholesterol \\
\hline Lipoplatin & Cisplatin & Anti-cancer & DPPG, Soy PC, cholesterol and PEG2000-DSPE \\
\hline LEP-ETU & Paclitaxel & Anti-cancer & DOPE and cholesterol \\
\hline
\end{tabular}




\begin{tabular}{|l|l|l|l|}
\hline Epaxal & Hepatitis A vaccine & Hepatitis A virus & DOPC and DOPE \\
\hline Inflexal V & Influenza vaccine & Influenza virus & DOPC and DOPE \\
\hline
\end{tabular}




\subsection{Prospective of liposomes in designing prophylaxis for RSV infection}

So far F, G, M, and small hydrophobic proteins have been identified as targets to avoid the RSV infection $[42,106,113,114]$. However, the role of F-protein is vital in the spread of the virus because targeting the G-protein can neutralize the virus, but the actual spread of the virus is only possible after inhibiting the F-protein [50]. Over a decade ago studies were suggesting that all three F-G- and RSV-SH protein inhibitors are required for complete success [132]. However, in the last decade researchers have realized the potential of F-protein for inhibiting RSV infection [133, 134]. Therefore, some recent studies have specifically targeted the F-protein [59, 60, 83]. The F-protein is structured in 9 domains; namely, signal peptide (SP), fusion peptide (FP), heptad repeat (HR) $1 \& 2$, transmembrane anchor (TM), cytoplasmic tail (CT), domain of 27 amino acids peptide (p27) and finally the F1 as well as F2 subunit domains [66]. The Fprotein can be synthesized as an inactive precursor (F0) having 574 amino acids that can be cleaved at $\mathrm{C}$-terminal and $\mathrm{N}$-terminal yielding $\mathrm{F} 1$ and $\mathrm{F} 2$ subunits, respectively [135]. Compounds can be designed to target the subunit regions which assist the fusion peptide's attachment to the host cells [60]. Perron and colleagues had tested a variety of compounds that target the F-1 subunit of the F-protein explicitly. One of these molecules, called GS-5806, was found to be a potent inhibitor of RSV with minimal toxicity and is undergoing phase-2 clinical trials. However, other compounds failed to meet the toxicity results achieved from the GS-5806. For these compounds, delivery systems like liposomes or nanoparticles could help lower the toxicity and achieve the desired physiological effect. For example, it is reported that liposomes not only can carry inhibitory protein GS-5806, but also help in triggering the fusion process and facilitating the RSV inhibition [59].

Liposomal research to date describes them as a system that can be used not only as a delivery system but also as adjuvants [10, 20, 52]. Liposome-based vaccine systems can be designed based on the type of immune response to be achieved; for example, MLV or LUV for $T_{H} 1$ immune response and SUV for the $T_{H} 2$ immune response $[20,136]$. Moreover, There are eight fundamental ways of using liposomes as drug delivery vehicles and hence, liposomes are multifaceted delivery systems (Figure 4) [137] and are capable of co-encapsulating compounds depending on their 
characteristics [138]. This structural attribute of liposomes can co-encapsulate compounds [138] and become a carrier of multiple proteins and other anti-RSV compounds. Liposomes can be designed to look like a virus by attaching various proteins to it [139]. Therefore, liposomes can be called 'multifaceted delivery systems' and hold the potential of entering the mainstream for designing the prophylaxis against RSV infection.

\section{Expert opinion}

Liposomes cover a variety of therapeutic areas including viral vaccine, cancer therapy, fungal diseases and analgesics, with more than a dozen liposome formulations already marketed and many are in clinical trials. Liposome formulations suit all ages including infant and older adults [140]. Since more than $90 \%$ of pulmonary material is a lipid, these lipid vesicles should not interfere with the functioning of the respiratory system. Moreover, many researchers have shown liposomes to be non-toxic [141, 142]. Therefore, liposomes being the most successful delivery system are now being considered as a carrier for many anti-RSV agents.

With no prophylaxis measures, RSV infection can become severe to lethal for prematurely born babies, children, and older adults. There is a need of immunoprophylaxis or anti-viral therapy to curtail increasing rates of hospitalization and mortality. In the development of a vaccine, the fate of vaccine depends on various stages, such as good laboratory practice (GLP), good manufacturing practice (GMP), good clinical research practice (CGRP) as well as the post-licensure studies. Of course, precise regulatory submission, statistical data analysis, and environmental factors contribute to an extent too [143]. At present, many anti-viral drugs, as well as monoclonal antibodies, are undergoing clinical trials. For the anti-RSV agents, liposomes can become a carrier to bring essential therapeutic effect with reduced toxicity.

Liposomes, due to their structural attributes, can encapsulate drugs within the bilayer, hydrophilic core or certain agents can be adsorbed/anchored on the surface of the liposomes. Therefore, consideration of co-encapsulation of the hydrophilic and 
lipophilic component, along with anchored ligands, could be the maximum usage of the structure of the liposome. Formulation of liposomal suspension with uniform vesicle distribution and minimal batch to batch variation is challenging but possible with precise manufacturing practice and quality ingredients. Further, the analysis of liposomal suspension has a variety of aspects to consider, such as percent encapsulation, size, surface charge, stability, and toxicity. Modern techniques like microfluidics can deliver uniform particles with higher encapsulation efficiency [144]. The stability of the liposomal suspension is can be customized for controlled release of the cargo based on the selection of the lipid composition. It is recommended that longer chain lipids with a high transition temperature (Tc) to be incorporated into the liposomal formulation for better encapsulation and extended stability [145]. For instance, palivizumab used in the RSV treatment, encapsulation of this drug into the higher Tc lipid could make the formulation stable by limiting the release of the drug on storage and may reduce its toxicity. Encapsulation of peptides is also considered challenging as many of the peptides are temperature sensitive. In such cases, considering a composition of different transition temperature lipids is recommended. Doing this will not only verify the trend of stability of the formulation but also will assist to match the anti-viral effect with the drug loss. On the other hand, selection of lipids is very important in designing antiviral liposome formulations, as certain lipids have shown anti-viral properties. Therefore, selection of such lipids would be a booster, in addition of the effect of the anti-viral agent. This can be also enhanced by using lipids that have immunomodulatory effects. The choice of synthesizing liposomes for the vaccine should complement the immune response elicited by the vaccine, tailoring liposomes for adjuvant or immuno-stimulatory effect dependent on the cargo to balance and generate desirable protection against RSV. 


\section{Funding}

The funding to publish this review article was from the grant NSF-CREST-(HRD1241701).

\section{Declaration of interest}

The authors have no relevant affiliations or financial involvement with any organization or entity with a financial interest in or financial conflict with the subject matter or materials discussed in the manuscript. This includes employment, consultancies, honoraria, stock ownership or options, expert testimony, grants or patents received or pending, or royalties.

\section{Reviewer disclosures}

Peer reviewers on this manuscript have no relevant financial or other relationships to disclose.

\section{Acknowledgements}

We would like to thank to Ms. Eva Dennis for helping us with artistic work related to figures. 


\section{References}

Papers of special note have been highlighted as:

* of interest

${ }^{* *}$ of considerable interest

1. Luchsinger V, Ampuero S, Palomino MA, et al. Comparison of virological profiles of respiratory syncytial virus and rhinovirus in acute lower tract respiratory infections in very young Chilean infants, according to their clinical outcome. Journal of clinical virology : the official publication of the Pan American Society for Clinical Virology. 2014 Sep;61(1):138-44. doi: 10.1016/j.jcv.2014.06.004. PubMed PMID: 24994006; eng.

2. (CDC) Cfdcap. Respiratory Syncytial Virus Infection (RSV) 2014 [updated December 4, 2014; cited 2016 April 27]. Available from: http://www.cdc.gov/rsv/about/transmission.html

3. Tregoning JS, Schwarze J. Respiratory viral infections in infants: causes, clinical symptoms, virology, and immunology. Clinical microbiology reviews. 2010 Jan;23(1):74-98. doi: 10.1128/cmr.00032-09. PubMed PMID: 20065326; PubMed Central PMCID: PMC2806659. eng.

4. Falsey AR, Hennessey PA, Formica MA, et al. Respiratory syncytial virus infection in elderly and high-risk adults. The New England journal of medicine. 2005 Apr 28;352(17):1749-59. doi: 10.1056/NEJMoa043951. PubMed PMID: 15858184; eng.

5. Shi T, McAllister DA, O'Brien KL, et al. Global, regional, and national disease burden estimates of acute lower respiratory infections due to respiratory syncytial virus in young children in 2015: a systematic review and modelling study. Lancet (London, England). 2017 Sep 2;390(10098):946-958. doi: 10.1016/s01406736(17)30938-8. PubMed PMID: 28689664; PubMed Central PMCID: PMC5592248. eng.

6. Borchers AT, Chang C, Gershwin ME, et al. Respiratory syncytial virus--a comprehensive review. Clinical reviews in allergy \& immunology. 2013 
Dec;45(3):331-79. doi: 10.1007/s12016-013-8368-9. PubMed PMID: 23575961; eng.

7. Kamphuis $T$, Stegmann $T$, Meijerhof $T$, et al. A virosomal respiratory syncytial virus vaccine adjuvanted with monophosphoryl lipid $A$ provides protection against viral challenge without priming for enhanced disease in cotton rats. Influenza and other respiratory viruses. 2013 Nov;7(6):1227-36. doi: 10.1111/irv.12112. PubMed PMID: 23575113; PubMed Central PMCID: PMC4634254. eng.

8. Handforth J, Sharland M, Friedland JS. Prevention of respiratory syncytial virus infection in infants: Palivizumab is effective but too expensive, and vaccines are unavailable as yet. BMJ: British Medical Journal. 2004;328(7447):1026.

9. Nicholson EG, Munoz FM. A Review of Therapeutics in Clinical Development for Respiratory Syncytial Virus and Influenza in Children. Clinical therapeutics. 2018 Aug;40(8):1268-1281. doi: 10.1016/j.clinthera.2018.06.014. PubMed PMID: 30077340; eng.

10. Perrie $Y$, Mohammed AR, Kirby DJ, et al. Vaccine adjuvant systems: enhancing the efficacy of sub-unit protein antigens. International journal of pharmaceutics. 2008 Dec 8;364(2):272-80. doi: 10.1016/j.ijpharm.2008.04.036. PubMed PMID: 18555624; eng.

11. Mohammed AR, Weston N, Coombes AG, et al. Liposome formulation of poorly water soluble drugs: optimisation of drug loading and ESEM analysis of stability. International journal of pharmaceutics. 2004 Nov 5;285(1-2):23-34. doi: 10.1016/j.ijpharm.2004.07.010. PubMed PMID: 15488676; eng.

12. Anderson $\mathrm{M}$, Omri A. The effect of different lipid components on the in vitro stability and release kinetics of liposome formulations. Drug delivery. 2004 JanFeb;11(1):33-9. doi: 10.1080/10717540490265243. PubMed PMID: 15168789; eng.

13. Bawage SS, Tiwari PM, Pillai S, et al. Recent advances in diagnosis, prevention, and treatment of human respiratory syncytial virus. Advances in virology. 2013;2013:595768. doi: 10.1155/2013/595768. PubMed PMID: 24382964; PubMed Central PMCID: PMC3872095. eng. 
14. Eroglu E, Tiwari PM, Waffo AB, et al. A nonviral pHEMA+chitosan nanospheremediated high-efficiency gene delivery system. International journal of nanomedicine. 2013;8:1403-15. doi: 10.2147/ijn.s43168. PubMed PMID: 23610520; PubMed Central PMCID: PMC3629879. eng.

15. Joshi S, Chaudhari AA, Dennis V, et al. Anti-RSV Peptide-Loaded Liposomes for the Inhibition of Respiratory Syncytial Virus. Bioengineering (Basel, Switzerland). 2018 May 9;5(2). doi: 10.3390/bioengineering5020037. PubMed PMID: 29747393; PubMed Central PMCID: PMC6027156. eng.

16. Gregoriadis G, Ryman BE. Lysosomal localization of -fructofuranosidasecontaining liposomes injected into rats. The Biochemical journal. 1972 Aug;129(1):123-33. PubMed PMID: 4646772; PubMed Central PMCID: PMC1174048. eng.

17. Gregoriadis G, Ryman BE. Fate of protein-containing liposomes injected into rats. An approach to the treatment of storage diseases. European journal of biochemistry. 1972 Jan 21;24(3):485-91. PubMed PMID: 4500958; eng.

18. Gregoriadis G, Leathwood PD, Ryman BE. Enzyme entrapment in liposomes. FEBS letters. 1971 Apr;14(2):95-99. PubMed PMID: 11945728; eng.

19. Perrie $\mathrm{Y}$, Kastner $\mathrm{E}$, Kaur R, et al. A case-study investigating the physicochemical characteristics that dictate the function of a liposomal adjuvant. Human vaccines \& immunotherapeutics. 2013 Jun;9(6):1374-81. doi: 10.4161/hv.24694. PubMed PMID: 23584249; PubMed Central PMCID: PMC3901835. eng.

20. Schwendener RA. Liposomes as vaccine delivery systems: a review of the recent advances. Therapeutic advances in vaccines. 2014 Nov;2(6):159-82. doi: 10.1177/2051013614541440. PubMed PMID: 25364509; PubMed Central PMCID: PMC4212474. eng.

21. Bulbake U, Doppalapudi S, Kommineni N, et al. Liposomal Formulations in Clinical Use: An Updated Review. Pharmaceutics. 2017 Mar 27;9(2). doi: 10.3390/pharmaceutics9020012. PubMed PMID: 28346375; PubMed Central PMCID: PMC5489929. eng. 
22. Dudas RA, Karron RA. Respiratory syncytial virus vaccines. Clinical microbiology reviews. 1998 Jul;11(3):430-9. PubMed PMID: 9665976; PubMed Central PMCID: PMC88889. eng.

23. Johnson SM, McNally BA, loannidis I, et al. Respiratory Syncytial Virus Uses CX3CR1 as a Receptor on Primary Human Airway Epithelial Cultures. PLoS pathogens. 2015 Dec;11(12):e1005318. doi: 10.1371/journal.ppat.1005318. PubMed PMID: 26658574; PubMed Central PMCID: PMC4676609. eng.

24. Hickling TP, Malhotra $\mathrm{R}$, Bright $\mathrm{H}$, et al. Lung surfactant protein $\mathrm{A}$ provides a route of entry for respiratory syncytial virus into host cells. Viral immunology. 2000;13(1):125-35. doi: 10.1089/vim.2000.13.125. PubMed PMID: 10733174; eng.

25. Malhotra $\mathrm{R}$, Ward $\mathrm{M}$, Bright $\mathrm{H}$, et al. Isolation and characterisation of potential respiratory syncytial virus receptor(s) on epithelial cells. Microbes and infection. 2003 Feb;5(2):123-33. PubMed PMID: 12650770; eng.

26. Tayyari F, Marchant $D$, Moraes $T J$, et al. Identification of nucleolin as a cellular receptor for human respiratory syncytial virus. Nature medicine. 2011 Aug 14;17(9):1132-5. doi: 10.1038/nm.2444. PubMed PMID: 21841784; eng.

27. Zhao X, Singh M, Malashkevich VN, et al. Structural characterization of the human respiratory syncytial virus fusion protein core. Proceedings of the National Academy of Sciences of the United States of America. 2000 Dec 19;97(26):14172-7. doi: 10.1073/pnas.260499197. PubMed PMID: 11106388; PubMed Central PMCID: PMC18890. eng.

28. Liljeroos L, Krzyzaniak MA, Helenius A, et al. Architecture of respiratory syncytial virus revealed by electron cryotomography. Proceedings of the National Academy of Sciences of the United States of America. $2013 \mathrm{Jul}$ 2;110(27):11133-8. doi: 10.1073/pnas.1309070110. PubMed PMID: 23776214; PubMed Central PMCID: PMC3703984. eng.

29. Vanover D, Smith DV, Blanchard EL, et al. RSV glycoprotein and genomic RNA dynamics reveal filament assembly prior to the plasma membrane. Nature communications. 2017 Sep 22;8(1):667. doi: 10.1038/s41467-017-00732-z. PubMed PMID: 28939853; PubMed Central PMCID: PMC5610308. eng. 
30. Kim HW, Canchola JG, Brandt CD, et al. Respiratory syncytial virus disease in infants despite prior administration of antigenic inactivated vaccine. American journal of epidemiology. 1969 Apr;89(4):422-34. PubMed PMID: 4305198; eng.

31. Long SS, Pickering LK, Prober CG. Principles and practice of pediatric infectious disease. Elsevier Health Sciences; 2012.

32. Karron RA, Buchholz UJ, Collins PL. Live-attenuated respiratory syncytial virus vaccines. Current topics in microbiology and immunology. 2013;372:259-84. doi: 10.1007/978-3-642-38919-1_13. PubMed PMID: 24362694; PubMed Central PMCID: PMC4794267. eng.

33. Wright PF, Karron RA, Belshe RB, et al. Evaluation of a live, cold-passaged, temperature-sensitive, respiratory syncytial virus vaccine candidate in infancy. The Journal of infectious diseases. 2000 Nov;182(5):1331-42. doi: 10.1086/315859. PubMed PMID: 11010838; eng.

34. Wright PF, Belshe RB, Kim HW, et al. Administration of a highly attenuated, live respiratory syncytial virus vaccine to adults and children. Infection and immunity. 1982 Jul;37(1):397-400. PubMed PMID: 7107009; PubMed Central PMCID: PMC347542. eng.

35. Wu H, Pfarr DS, Johnson S, et al. Development of motavizumab, an ultra-potent antibody for the prevention of respiratory syncytial virus infection in the upper and lower respiratory tract. Journal of molecular biology. 2007 May 4;368(3):652-65. doi: 10.1016/j.jmb.2007.02.024. PubMed PMID: 17362988; eng.

36. Sun Z, Pan Y, Jiang S, et al. Respiratory syncytial virus entry inhibitors targeting the F protein. Viruses. 2013 Jan 16;5(1):211-25. doi: 10.3390/v5010211. PubMed PMID: 23325327; PubMed Central PMCID: PMC3564118. eng.

37. Piedimonte G, Perez MK. Respiratory syncytial virus infection and bronchiolitis. Pediatrics in review. 2014 Dec;35(12):519-30. doi: 10.1542/pir.35-12-519. PubMed PMID: 25452661; PubMed Central PMCID: PMC5029757. eng.

38. Simões EAF, DeVincenzo JP, Boeckh M, et al. Challenges and opportunities in developing respiratory syncytial virus therapeutics. The Journal of infectious diseases. 2015;211 Suppl 1(Suppl 1):S1-S20. doi: 10.1093/infdis/jiu828. PubMed PMID: 25713060; eng. 
39. Simoes EA, DeVincenzo JP, Boeckh M, et al. Challenges and opportunities in developing respiratory syncytial virus therapeutics. The Journal of infectious diseases. 2015 Mar 15;211 Suppl 1:S1-S20. doi: 10.1093/infdis/jiu828. PubMed PMID: 25713060; PubMed Central PMCID: PMC4345819. eng.

40. ClinicalTrials.gov. Respiratory Syncytial Virus Infections: ClinicalTrials.gov; 2017 [cited 2017 Sep 22 2017]. Available from:

https://clinicaltrials.gov/ct2/results?recrs=a\&cond=\%22Respiratory+Syncytial+Vir us+Infections $\% 22$

41. Berg JT, Lee ST, Thepen T, et al. Depletion of alveolar macrophages by liposome-encapsulated dichloromethylene diphosphonate. Journal of applied physiology (Bethesda, Md : 1985). 1993 Jun;74(6):2812-9. doi: 10.1152/jappl.1993.74.6.2812. PubMed PMID: 8365985; eng.

42. Mader D, Huang $Y$, Wang $C$, et al. Liposome encapsulation of a soluble recombinant fragment of the respiratory syncytial virus (RSV) G protein enhances immune protection and reduces lung eosinophilia associated with virus challenge. Vaccine. 2000 Jan 6;18(11-12):1110-7. PubMed PMID: 10590333; eng.

43. Huang $\mathrm{Y}$, Anderson $\mathrm{R}$. Enhanced immune protection by a liposomeencapsulated recombinant respiratory syncytial virus (RSV) vaccine using immunogenic lipids from Deinococcus radiodurans. Vaccine. 2002 Feb 22;20(1112):1586-92. PubMed PMID: 11858866; eng.

44. Andries K, Moeremans M, Gevers T, et al. Substituted benzimidazoles with nanomolar activity against respiratory syncytial virus. Antiviral research. 2003 Nov;60(3):209-19. PubMed PMID: 14638397; eng.

45. Wyde PR, Chetty SN, Timmerman P, et al. Short duration aerosols of JNJ 2408068 (R170591) administered prophylactically or therapeutically protect cotton rats from experimental respiratory syncytial virus infection. Antiviral research. 2003 Nov;60(3):221-31. PubMed PMID: 14638398; eng.

46. Mohan T, Verma P, Rao DN. Novel adjuvants \& delivery vehicles for vaccines development: a road ahead. The Indian journal of medical research. 2013 
Nov;138(5):779-95. PubMed PMID: 24434331; PubMed Central PMCID: PMC3928709. eng.

47. ClinicalTrials.gov. A Study to Determine the Safety and Efficacy of the RSV F Vaccine to Protect Infants Via Maternal Immunization: ClinicalTrials.gov; 2017 [cited 2017 Sep 22 2017]. Available from:

https://clinicaltrials.gov/ct2/show/NCT02624947?recrs=a\&cond=\%22Respiratory +Syncytial+Virus+Infections $\% 22 \&$ draw $=1$ \&rank $=8$

48. August $A$, editor RSV $F$ vaccine: phase 2 clinical trial to protect infants via maternal immunization. XXI FIGO World Congress of Gynecology and Obstetrics. 2015; 201520015.

49. Hughson FM. Structural characterization of viral fusion proteins. Current biology : CB. 1995 Mar 1;5(3):265-74. PubMed PMID: 7780737; eng.

50. Hancock GE, Speelman DJ, Frenchick PJ, et al. Formulation of the purified fusion protein of respiratory syncytial virus with the saponin QS-21 induces protective immune responses in Balb/c mice that are similar to those generated by experimental infection. Vaccine. 1995 Mar;13(4):391-400. PubMed PMID: 7793137; eng.

51. Koenig S. Methods of enhancing activity of vaccines and vaccine compositions. Google Patents; 2003.

52. Allison AG, Gregoriadis G. Liposomes as immunological adjuvants. Nature. 1974 Nov 15;252(5480):252. PubMed PMID: 4424229; eng.

53. Perrie $Y$, Frederik PM, Gregoriadis G. Liposome-mediated DNA vaccination: the effect of vesicle composition. Vaccine. 2001 Apr 30;19(23-24):3301-10. PubMed PMID: 11312029; eng.

54. Saez-Llorens X, Castano E, Null D, et al. Safety and pharmacokinetics of an intramuscular humanized monoclonal antibody to respiratory syncytial virus in premature infants and infants with bronchopulmonary dysplasia. The MEDI-493 Study Group. The Pediatric infectious disease journal. 1998 Sep;17(9):787-91. PubMed PMID: 9779762; eng. 
55. Palivizumab, a Humanized Respiratory Syncytial Virus Monoclonal Antibody, Reduces Hospitalization From Respiratory Syncytial Virus Infection in High-risk Infants. Pediatrics. 1998 Sep;102(3):531-7. PubMed PMID: 9724660; eng.

56. Cingoz O. Motavizumab. mAbs. 2009 Sep-Oct;1(5):439-42. PubMed PMID: 20065632; PubMed Central PMCID: PMC2759493. eng.

57. AstraZeneca. AstraZeneca discontinues development of motavizumab for RSV prophylaxis indication: AstraZeneca; 2010 [cited 2017 SEP-22-2017].

58. Reichert JM. Antibodies to watch in 2017. mAbs. 2017 Feb/Mar;9(2):167-181. doi: 10.1080/19420862.2016.1269580. PubMed PMID: 27960628; PubMed Central PMCID: PMC5297518. eng.

59. Samuel D, Xing W, Niedziela-Majka A, et al. GS-5806 inhibits pre- to postfusion conformational changes of the respiratory syncytial virus fusion protein. Antimicrobial agents and chemotherapy. 2015 Nov;59(11):7109-12. doi: 10.1128/aac.00761-15. PubMed PMID: 26324264; PubMed Central PMCID: PMC4604407. eng.

60. Perron M, Stray K, Kinkade A, et al. GS-5806 Inhibits a Broad Range of Respiratory Syncytial Virus Clinical Isolates by Blocking the Virus-Cell Fusion Process. Antimicrobial agents and chemotherapy. 2015 Dec 14;60(3):1264-73. doi: 10.1128/aac.01497-15. PubMed PMID: 26666922; PubMed Central PMCID: PMC4776015. eng.

61. Douglas JL, Panis ML, Ho E, et al. Small molecules VP-14637 and JNJ-2408068 inhibit respiratory syncytial virus fusion by similar mechanisms. Antimicrobial agents and chemotherapy. 2005 Jun;49(6):2460-6. doi: 10.1128/aac.49.6.24602466.2005. PubMed PMID: 15917547; PubMed Central PMCID: PMC1140497. eng.

62. Israel S, Rusch S, DeVincenzo J, et al., editors. Effect of Oral JNJ-53718678 (JNJ-678) on Disease Severity in Healthy Adult Volunteers Experimentally Inoculated With Live Respiratory Syncytial Virus (RSV): A Placebo-Controlled Challenge Study. Open Forum Infectious Diseases; 2016: Oxford University Press. 
63. Shook BC, Lin K. Recent Advances in Developing Antiviral Therapies for Respiratory Syncytial Virus. Topics in current chemistry (Cham). 2017 Apr;375(2):40. doi: 10.1007/s41061-017-0129-4. PubMed PMID: 28324595; eng.

64. ClinicalTrials.gov. Safety, Pharmacokinetics and Antiviral Activity of RV521 Against RSV: ClinicalTrials.gov; 2017 [cited 2017 SEP 25 2017]. Available from: https://clinicaltrials.gov/ct2/show/NCT03258502? recrs=a\&cond=\%22Respiratory +Syncytial+Virus+Infections \%22\&draw=1\&rank=1

65. Wellspring. A Randomized, double-blind, placebo-controlled, 2-part study of orally administered AK0529 to evaluate the safety, tolerability, pharmacokinetics and antiviral effect of single and multiple dosing in hospitalized infants with respiratory syncytial virus infection: Wellspring; 2017 [cited 2017 Sep 22 2017]. Available from: https://search.wellspringsoftware.net/clinical-trial/NCT02654171

66. Heylen E, Neyts J, Jochmans D. Drug candidates and model systems in respiratory syncytial virus antiviral drug discovery. Biochemical pharmacology. 2017 Mar 1;127:1-12. doi: 10.1016/j.bcp.2016.09.014. PubMed PMID: 27659812; eng.

67. ClinicalTrials.gov. Safety Study of Oral BTA9881 to Treat RSV Infection: ClinicalTrials.gov; 2017 [cited 2017 Sep 22 2017]. Available from: https://clinicaltrials.gov/ct2/show/NCT00504907

68. Drugbank. VP-14637: Drug Bank; 2017 [cited 2017 Sep 22 2017]. Available from: https://www.drugbank.ca/drugs/DB12195

69. Drugbank. BTA9881: Drugbank; 2016 [cited 2017 Sep 22 2017]. Available from: https://www.drugbank.ca/drugs/DB05226

70. Bonfanti JF, Roymans D. Prospects for the development of fusion inhibitors to treat human respiratory syncytial virus infection. Current opinion in drug discovery \& development. 2009 Jul;12(4):479-87. PubMed PMID: 19562644; eng.

71. Brookes DW, Coates $\mathrm{M}$, Allen $\mathrm{H}$, et al. Late therapeutic intervention with a respiratory syncytial virus L-protein polymerase inhibitor, PC786, on respiratory syncytial virus infection in human airway epithelium. British journal of 
pharmacology. 2018 Jun;175(12):2520-2534. doi: 10.1111/bph.14221. PubMed PMID: 29579332; PubMed Central PMCID: PMC5980447. eng.

72. Noton SL, Nagendra K, Dunn EF, et al. Respiratory Syncytial Virus Inhibitor AZ27 Differentially Inhibits Different Polymerase Activities at the Promoter. J Virol. 2015 Aug;89(15):7786-98. doi: 10.1128/jvi.00530-15. PubMed PMID: 25995255; PubMed Central PMCID: PMC4505683. eng.

73. Nikitenko AA, Raifeld YE, Wang TZ. The discovery of RFI-641 as a potent and selective inhibitor of the respiratory syncytial virus. Bioorganic \& medicinal chemistry letters. 2001 Apr 23;11(8):1041-4. PubMed PMID: 11327584; eng.

74. Rouan MC, Gevers T, Roymans D, et al. Pharmacokinetics-pharmacodynamics of a respiratory syncytial virus fusion inhibitor in the cotton rat model. Antimicrobial agents and chemotherapy. 2010 Nov;54(11):4534-9. doi: 10.1128/aac.00643-10. PubMed PMID: 20823290; PubMed Central PMCID: PMC2976145. eng.

75. Ispas G, Koul A, Verbeeck J, et al. Antiviral Activity of TMC353121, a Respiratory Syncytial Virus (RSV) Fusion Inhibitor, in a Non-Human Primate Model. PloS one. 2015;10(5):e0126959. doi: 10.1371/journal.pone.0126959. PubMed PMID: 26010881; PubMed Central PMCID: PMC4444337. eng.

76. Huntley CC, Weiss WJ, Gazumyan A, et al. RFI-641, a potent respiratory syncytial virus inhibitor. Antimicrobial agents and chemotherapy. 2002 Mar;46(3):841-7. PubMed PMID: 11850270; PubMed Central PMCID: PMC127488. eng.

77. Razinkov V, Gazumyan A, Nikitenko A, et al. RFI-641 inhibits entry of respiratory syncytial virus via interactions with fusion protein. Chemistry \& biology. 2001 Jul;8(7):645-59. PubMed PMID: 11451666; eng.

78. Wyde PR, Moore-Poveda DK, O'Hara B, et al. CL387626 exhibits marked and unusual antiviral activity against respiratory syncytial virus in tissue culture and in cotton rats. Antiviral research. 1998 Apr;38(1):31-42. PubMed PMID: 9614002; eng.

79. Morton CJ, Cameron R, Lawrence LJ, et al. Structural characterization of respiratory syncytial virus fusion inhibitor escape mutants: homology model of the 
F protein and a syncytium formation assay. Virology. $2003 \mathrm{Jul}$ 5;311(2):275-88. PubMed PMID: 12842618; eng.

80. Wang E, Sun X, Qian Y, et al. Both heptad repeats of human respiratory syncytial virus fusion protein are potent inhibitors of viral fusion. Biochemical and biophysical research communications. 2003 Mar 14;302(3):469-75. PubMed PMID: 12615056; eng.

81. Ni L, Zhao L, Qian Y, et al. Design and characterization of human respiratory syncytial virus entry inhibitors. Antiviral therapy. 2005;10(7):833-40. PubMed PMID: 16312179; eng.

82. Magro M, Andreu D, Gomez-Puertas $\mathrm{P}$, et al. Neutralization of human respiratory syncytial virus infectivity by antibodies and low-molecular-weight compounds targeted against the fusion glycoprotein. J Virol. 2010 Aug;84(16):7970-82. doi: 10.1128/jvi.00447-10. PubMed PMID: 20534864; PubMed Central PMCID: PMC2916552. eng.

83. Singh SR, Tiwari PM, Dennis VA. Anti respiratory syncytial virus peptide functionalized gold nanoparticles. Google Patents; 2014.

84. Cianci C, Genovesi EV, Lamb L, et al. Oral efficacy of a respiratory syncytial virus inhibitor in rodent models of infection. Antimicrobial agents and chemotherapy. 2004 Jul;48(7):2448-54. doi: 10.1128/aac.48.7.2448-2454.2004. PubMed PMID: 15215093; PubMed Central PMCID: PMC434195. eng.

85. Murawski MR, McGinnes LW, Finberg RW, et al. Newcastle disease virus-like particles containing respiratory syncytial virus $G$ protein induced protection in BALB/c mice, with no evidence of immunopathology [Research Support, N I H , Extramural Research Support, Non-U S Gov't]. J Virol. 2010;84(2):1110-23.

86. Kim AR, Lee $\mathrm{DH}$, Lee $\mathrm{SH}$, et al. Protection induced by virus-like particle vaccine containing tandem repeat gene of respiratory syncytial virus $\mathrm{G}$ protein. PloS one. 2018;13(1):e0191277. doi: 10.1371/journal.pone.0191277. PubMed PMID: 29338045; PubMed Central PMCID: PMC5770062. eng.

87. Cai M, Wang C, Li Y, et al. Virus-like particle vaccine by intranasal vaccination elicits protective immunity against respiratory syncytial viral infection in mice. 
Acta biochimica et biophysica Sinica. 2017 Jan;49(1):74-82. doi: 10.1093/abbs/gmw118. PubMed PMID: 27974288; eng.

88. Smith $\mathrm{G}$, Raghunandan $\mathrm{R}, \mathrm{Wu} \mathrm{Y}$, et al. Respiratory syncytial virus fusion glycoprotein expressed in insect cells form protein nanoparticles that induce protective immunity in cotton rats. PloS one. 2012;7(11):e50852. doi: 10.1371/journal.pone.0050852. PubMed PMID: 23226404; PubMed Central PMCID: PMC3511306. eng.

89. Quan FS, Kim Y, Lee S, et al. Viruslike particle vaccine induces protection against respiratory syncytial virus infection in mice. The Journal of infectious diseases. 2011 Oct 1;204(7):987-95. doi: 10.1093/infdis/jir474. PubMed PMID: 21881112; PubMed Central PMCID: PMC3164432. eng.

90. Tiwari G, Tiwari R, Sriwastawa B, et al. Drug delivery systems: An updated review. International journal of pharmaceutical investigation. 2012 Jan;2(1):2-11. doi: 10.4103/2230-973x.96920. PubMed PMID: 23071954; PubMed Central PMCID: PMC3465154. eng.

91. Jorquera PA, Tripp RA. Synthetic Biodegradable Microparticle and Nanoparticle Vaccines against the Respiratory Syncytial Virus. Vaccines. 2016 Dec 2;4(4). doi: 10.3390/vaccines4040045. PubMed PMID: 27918420; PubMed Central PMCID: PMC5192365. eng.

92. Tiwari PM, Eroglu E, Bawage SS, et al. Enhanced intracellular translocation and biodistribution of gold nanoparticles functionalized with a cell-penetrating peptide (VG-21) from vesicular stomatitis virus. Biomaterials. 2014 Nov;35(35):9484-94. doi: 10.1016/j.biomaterials.2014.07.032. PubMed PMID: 25154664; eng.

93. Bawage SS, Tiwari PM, Singh A, et al. Gold nanorods inhibit respiratory syncytial virus by stimulating the innate immune response. Nanomedicine : nanotechnology, biology, and medicine. 2016 Nov;12(8):2299-2310. doi: 10.1016/j.nano.2016.06.006. PubMed PMID: 27381068; PubMed Central PMCID: PMC5116403. eng.

94. Sun L, Singh AK, Vig K, et al. Silver nanoparticles inhibit replication of respiratory syncytial virus. Journal of Biomedical Nanotechnology. 2008;4(2):149-158. 
95. Boyoglu S, Vig K, Pillai S, et al. Enhanced delivery and expression of a nanoencapsulated DNA vaccine vector for respiratory syncytial virus.

Nanomedicine : nanotechnology, biology, and medicine. 2009 Dec;5(4):463-72. doi: 10.1016/j.nano.2009.02.004. PubMed PMID: 19341819; eng.

96. Biswas S, Chattopadhyay M, Sen KK, et al. Development and characterization of alginate coated low molecular weight chitosan nanoparticles as new carriers for oral vaccine delivery in mice. Carbohydr Polym. 2015;121:403-10.

97. Tree JA, Bembridge G, Hou S, et al. An assessment of different DNA delivery systems for protection against respiratory syncytial virus infection in the murine model: gene-gun delivery induces IgG in the lung. Vaccine. 2004 Jun 23;22(19):2438-43. doi: 10.1016/j.vaccine.2003.11.069. PubMed PMID: 15193407; eng.

98. Wang $\mathrm{T}$, Jiang $\mathrm{H}$, Zhao $\mathrm{Q}$, et al. Enhanced mucosal and systemic immune responses obtained by porous silica nanoparticles used as an oral vaccine adjuvant: effect of silica architecture on immunological properties. International journal of pharmaceutics. 2012 Oct 15;436(1-2):351-8. doi: 10.1016/j.jpharm.2012.06.028. PubMed PMID: 22721849; eng.

99. Vallhov H, Gabrielsson S, Stromme M, et al. Mesoporous silica particles induce size dependent effects on human dendritic cells. Nano letters. 2007 Dec;7(12):3576-82. doi: 10.1021/nI0714785. PubMed PMID: 17975942; eng.

100. Nuhn L, Van Hoecke L, Deswarte K, et al. Potent anti-viral vaccine adjuvant based on $\mathrm{pH}$-degradable nanogels with covalently linked small molecule imidazoquinoline TLR7/8 agonist. Biomaterials. 2018 Sep;178:643-651. doi: 10.1016/j.biomaterials.2018.03.026. PubMed PMID: 29573820; eng.

101. Shilakari Asthana G, Sharma PK, Asthana A. In Vitro and In Vivo Evaluation of Niosomal Formulation for Controlled Delivery of Clarithromycin. Scientifica. 2016;2016:6492953. doi: 10.1155/2016/6492953. PubMed PMID: 27293976; PubMed Central PMCID: PMC4884864. eng.

102. Donalisio M, Rusnati M, Cagno V, et al. Inhibition of human respiratory syncytial virus infectivity by a dendrimeric heparan sulfate-binding peptide. Antimicrobial 
agents and chemotherapy. 2012 Oct;56(10):5278-88. doi: 10.1128/aac.0077112. PubMed PMID: 22850525; PubMed Central PMCID: PMC3457392. eng.

103. Yan Y, Björnmalm M, Caruso F. Assembly of layer-by-layer particles and their interactions with biological systems. Chemistry of Materials. 2013;26(1):452-460.

104. Bangham AD, Standish MM, Watkins JC. Diffusion of univalent ions across the lamellae of swollen phospholipids. Journal of molecular biology. 1965 Aug;13(1):238-52. PubMed PMID: 5859039; eng.

105. Rappuoli R, Mandl CW, Black S, et al. Vaccines for the twenty-first century society. Nature reviews Immunology. 2011 Nov 4;11(12):865-72. doi: 10.1038/nri3085. PubMed PMID: 22051890; eng.

106. Connors M, Kulkarni $A B$, Collins PL, et al. Resistance to respiratory syncytial virus (RSV) challenge induced by infection with a vaccinia virus recombinant expressing the RSV M2 protein (Vac-M2) is mediated by CD8+ T cells, while that induced by Vac-F or Vac-G recombinants is mediated by antibodies. J Virol. 1992 Feb;66(2):1277-81. PubMed PMID: 1731105; PubMed Central PMCID: PMC240842. eng.

107. Harris J, Werling D. Binding and entry of respiratory syncytial virus into host cells and initiation of the innate immune response. Cellular microbiology. 2003 Oct;5(10):671-80. PubMed PMID: 12969373; eng.

108. Benoit $A$, Huang $\mathrm{Y}$, Proctor J, et al. Effects of alveolar macrophage depletion on liposomal vaccine protection against respiratory syncytial virus (RSV). Clinical and experimental immunology. 2006 Jul;145(1):147-54. doi: 10.1111/j.13652249.2006.03114.x. PubMed PMID: 16792685; PubMed Central PMCID: PMC1941998. eng.

109. Valstar D, Schijf M, Storm G, et al. Depletion of alveolar macrophages by liposome-encapsulated clodronate in mice and rats. Low molecular weight chemical-induced occupational asthma The focus on alveolar macrophages. 2004:19.

110. Gordon SB, Read RC. Macrophage defences against respiratory tract infections. British medical bulletin. 2002;61:45-61. doi: 10.1093/bmb/61.1.45. PubMed PMID: 11997298; eng. 
111. Geall AJ, Verma A, Otten GR, et al. Nonviral delivery of self-amplifying RNA vaccines. Proceedings of the National Academy of Sciences of the United States of America. 2012 Sep 4;109(36):14604-9. doi: 10.1073/pnas.1209367109. PubMed PMID: 22908294; PubMed Central PMCID: PMC3437863. eng.

112. Lee YT, Ko EJ, Hwang HS, et al. Respiratory syncytial virus-like nanoparticle vaccination induces long-term protection without pulmonary disease by modulating cytokines and T-cells partially through alveolar macrophages. International journal of nanomedicine. 2015;10:4491-505. doi: 10.2147/ijn.s83493. PubMed PMID: 26203246; PubMed Central PMCID: PMC4508085. eng.

113. Hendricks GL, Velazquez L, Pham S, et al. Heparin octasaccharide decoy liposomes inhibit replication of multiple viruses. Antiviral research. 2015 Apr;116:34-44. doi: 10.1016/j.antiviral.2015.01.008. PubMed PMID: 25637710; PubMed Central PMCID: PMC4988063. eng.

114. Li Y, To J, Verdia-Baguena $\mathrm{C}$, et al. Inhibition of the human respiratory syncytial virus small hydrophobic protein and structural variations in a bicelle environment. J Virol. 2014 Oct;88(20):11899-914. doi: 10.1128/jvi.00839-14. PubMed PMID: 25100835; PubMed Central PMCID: PMC4178740. eng.

115. Shafique $M$, Meijerhof $\mathrm{T}$, Wilschut $\mathrm{J}$, et al. Evaluation of an intranasal virosomal vaccine against respiratory syncytial virus in mice: effect of TLR2 and NOD2 ligands on induction of systemic and mucosal immune responses. PloS one. 2013;8(4):e61287. doi: 10.1371/journal.pone.0061287. PubMed PMID: 23593453; PubMed Central PMCID: PMC3620164. eng.

116. Numata M, Nagashima $Y$, Moore ML, et al. Phosphatidylglycerol provides shortterm prophylaxis against respiratory syncytial virus infection. Journal of lipid research. 2013 Aug;54(8):2133-43. doi: 10.1194/jlr.M037077. PubMed PMID: 23749985; PubMed Central PMCID: PMC3708363. eng.

117. Numata M, Chu HW, Dakhama A, et al. Pulmonary surfactant phosphatidylglycerol inhibits respiratory syncytial virus-induced inflammation and infection. Proceedings of the National Academy of Sciences of the United States 
of America. 2010 Jan 5;107(1):320-5. doi: 10.1073/pnas.0909361107. PubMed PMID: 20080799; PubMed Central PMCID: PMC2806703. eng.

118. Baas T. Giving RSV some POP (G). Science-Business eXchange. 2010;3(2):3535.

119. Abbott S, Blazek N, Foster M, et al. Naturally occurring lipid blocks RSV in lungs. Infectious Diseases in Children. 2010;23(2):52.

120. Hilmarsson $\mathrm{H}$, Traustason BS, Kristmundsdottir $\mathrm{T}$, et al. Virucidal activities of medium- and long-chain fatty alcohols and lipids against respiratory syncytial virus and parainfluenza virus type 2: comparison at different $\mathrm{pH}$ levels. Archives of virology. 2007;152(12):2225-36. doi: 10.1007/s00705-007-1063-5. PubMed PMID: 17891329; eng.

121. Isaacs $\mathrm{CE}$, Litov RE, Thormar H. Antimicrobial activity of lipids added to human milk, infant formula, and bovine milk. The Journal of nutritional biochemistry. 1995 Jul;6(7):362-366. PubMed PMID: 12049996; eng.

122. Guest K, O'Brien M. Treating acute bronchiolitis associated with RSV. Am Fam Physician. 2004;69:325-30.

123. Donnelly BW. Vitamin A and respiratory syncytial virus infection. Archives of pediatrics \& adolescent medicine. 1996;150(8):882-882.

124. Li Y, Jiang R, Ooi LS, et al. Antiviral triterpenoids from the medicinal plant Schefflera heptaphylla. Phytotherapy research : PTR. 2007 May;21(5):466-70. doi: 10.1002/ptr.1962. PubMed PMID: 17357972; eng.

125. Esimone CO, Eck G, Duong TN, et al. Potential anti-respiratory syncytial virus lead compounds from Aglaia species. Pharmazie. 2008;63(10):768-73.

126. Antonietti M, Förster S. Vesicles and Liposomes: A Self-Assembly Principle Beyond Lipids. Advanced Materials. 2003;15(16):1323-1333. doi: 10.1002/adma.200300010.

127. Mabrey S, Sturtevant JM. Investigation of phase transitions of lipids and lipid mixtures by sensitivity differential scanning calorimetry. Proceedings of the National Academy of Sciences of the United States of America. 1976 Nov;73(11):3862-6. PubMed PMID: 1069270; PubMed Central PMCID: PMC431243. eng. 
128. Gregoriadis G, Senior J, Wolff B, et al. Fate of Liposomes In Vivo: Control Leading to Targeting. In: Gregoriadis G, Poste G, Senior J, et al., editors. Receptor-Mediated Targeting of Drugs: Springer US; 1984. p. 243-266.

129. Bhandary S, Basu R, Das S, et al. Comparison of the effect of anti-hyperlipidemic drugs from different groups on the phase profile of liposomal membrane-a fluorescence anisotropy study. Phase Transitions. 2010;83(7):518-525.

130. Sharma A, Sharma US. Liposomes in drug delivery: progress and limitations. International journal of pharmaceutics. 1997;154(2):123-140.

131. Webb MS, Boman NL, Wiseman DJ, et al. Antibacterial efficacy against an in vivo Salmonella typhimurium infection model and pharmacokinetics of a liposomal ciprofloxacin formulation. Antimicrobial agents and chemotherapy. 1998 Jan;42(1):45-52. PubMed PMID: 9449259; PubMed Central PMCID: PMC105454. eng.

132. Heminway BR, Yu Y, Tanaka Y, et al. Analysis of respiratory syncytial virus F, G, and SH proteins in cell fusion. Virology. 1994 May 1;200(2):801-5. doi: 10.1006/viro.1994.1245. PubMed PMID: 8178462; eng.

133. Techaarpornkul S, Barretto N, Peeples ME. Functional analysis of recombinant respiratory syncytial virus deletion mutants lacking the small hydrophobic and/or attachment glycoprotein gene. J Virol. 2001 Aug;75(15):6825-34. doi: 10.1128/jvi.75.15.6825-6834.2001. PubMed PMID: 11435561; PubMed Central PMCID: PMC114409. eng.

134. Battles MB, Langedijk JP, Furmanova-Hollenstein $P$, et al. Molecular mechanism of respiratory syncytial virus fusion inhibitors. Nature chemical biology. 2016 Feb;12(2):87-93. doi: 10.1038/nchembio.1982. PubMed PMID: 26641933; PubMed Central PMCID: PMC4731865. eng.

135. McLellan JS, Ray WC, Peeples ME. Structure and function of respiratory syncytial virus surface glycoproteins. Current topics in microbiology and immunology. 2013;372:83-104. doi: 10.1007/978-3-642-38919-1_4. PubMed PMID: 24362685; PubMed Central PMCID: PMC4211642. eng.

136. Badiee A, Khamesipour A, Samiei A, et al. The role of liposome size on the type of immune response induced in BALB/c mice against leishmaniasis: rgp63 as a 
model antigen. Experimental parasitology. 2012 Dec;132(4):403-9. doi: 10.1016/j.exppara.2012.09.001. PubMed PMID: 22982807; eng.

137. Joshi S. Liposomes: a multifaceted delivery system: Aston University; 2017.

138. Joshi S, Hussain MT, Roces CB, et al. Microfluidics based manufacture of liposomes simultaneously entrapping hydrophilic and lipophilic drugs. International journal of pharmaceutics. 2016 Nov 30;514(1):160-168. doi: 10.1016/j.jpharm.2016.09.027. PubMed PMID: 27863660; eng.

139. Zurbriggen R, Amacker M, Krammer AR. Immunopotentiating reconstituted influenza virosomes. Liposome technology. 2006;1:85-96.

140. Seibel NL, Shad AT, Bekersky I, et al. Safety, Tolerability, and Pharmacokinetics of Liposomal Amphotericin B in Immunocompromised Pediatric Patients.

Antimicrobial agents and chemotherapy. 2017 Feb;61(2). doi:

10.1128/aac.01477-16. PubMed PMID: 27855062; PubMed Central PMCID: PMC5278758. eng.

141. Joshi S, Chaudhari AA, Dennis V, et al. Anti-RSV Peptide-Loaded Liposomes for the Inhibition of Respiratory Syncytial Virus. Bioengineering. 2018;5(2):37.

142. Perrie $Y$, Mohammed AR, Kirby DJ, et al. Vaccine adjuvant systems: enhancing the efficacy of sub-unit protein antigens. International journal of pharmaceutics. 2008;364(2):272-280.

143. Nalin DR. Evidence based vaccinology. Vaccine. 2002 Feb 22;20(11-12):162430. PubMed PMID: 11858871; eng.

144. Joshi S, Hussain MT, Roces CB, et al. Microfluidics based manufacture of liposomes simultaneously entrapping hydrophilic and lipophilic drugs. International journal of pharmaceutics. 2016;514(1):160-168.

145. Ali MH, Moghaddam B, Kirby DJ, et al. The role of lipid geometry in designing liposomes for the solubilisation of poorly water soluble drugs. Int J Pharm. 2013 Aug 30;453(1):225-32. doi: 10.1016/j.ijpharm.2012.06.056. PubMed PMID: 22766442; eng. 


\section{Reference annotations}

${ }^{* *}$ Reference-10: The article describes use of adjuvant systems, which we think would be vital in developing anti-RSV formulation.

${ }^{* *}$ Reference-15: The article describes inhibition of RSV by anti-RSV peptide loaded into the liposome. It is also recommended by the Referee-1.

${ }^{*}$ Reference-39: The authors has very well highlighted the challenges and opportunities in developing RSV therapeutics.

${ }^{* *}$ Reference-108: The author describes effects of alveolar macrophages on liposomal vaccine protection.

${ }^{* *}$ Reference- 117: The article describes inhibition of RSV by different lipids. 


\section{Figure legends}

Figure 1. Structure of respiratory syncytial virus with a single-stranded RNA, surface as well as matrix proteins.

Figure 2. Schematic representing lungs before the RSV infection (inset showing healthy bronchus) (A), cell level infection of the RSV (B), and the lungs post-RSV infection (inset showing constriction of bronchus) (C). Stage of cell level infection 1 (RSV in the body (1), attachment (2), fusion (3), RNA release (4), Translation (5a) and replication (5b) followed by the assembly (6), budding (7) and release of RSV (8).

Figure 3. Classification of liposomes based on their size. MLV = Multilamellar vesicle, LUV = Large unilamellar vesicle, SUV= Small unilamellar vesicle [104, 105].

Figure 4. The schematic showing 'multifaceted nature of the liposomes' [105]. Total 8 fundamental ways to take structural advantage of liposomes as a carrier for different molecules (represented in blue, orange and green). (a) Empty liposomes (b) encapsulation in the hydrophilic core, (c) co-encapsulation in hydrophilic core and lipophilic bilayer, (d) encapsulation in the hydrophilic core and loading on the liposome surface, (e) encapsulation in the bilayer, (f) encapsulation in the bilayer and loading on the liposome surface, (g) loading on the liposome surface, (h) encapsulation in the hydrophilic core as well as lipophilic bilayer and loading on the liposome surface. 
Structure of respiratory syncytial virus with a single-stranded RNA, surface as well as matrix proteins.

$$
228 \times 163 \mathrm{~mm}(300 \times 300 \mathrm{DPI})
$$


Schematic representing lungs before the RSV infection (inset showing healthy bronchus) (A), cell level infection of the RSV (B), and the lungs post-RSV infection (inset showing constriction of bronchus) (C). Stage of cell level infection 1 (RSV in the body (1), attachment (2), fusion (3), RNA release (4), Translation (5a) and replication (5b) followed by the assembly (6), budding (7) and release of RSV (8). 
Classification of liposomes based on their size. MLV = Multilamellar vesicle, LUV = Large unilamellar vesicle, SUV $=$ Small unilamellar vesicle $[104,105]$.

$50 \times 17 \mathrm{~mm}(300 \times 300 \mathrm{DPI})$ 


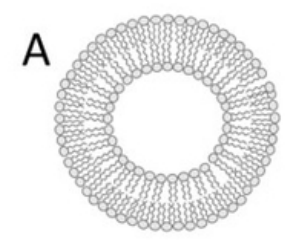

B

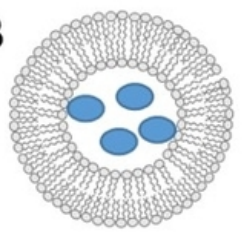

C
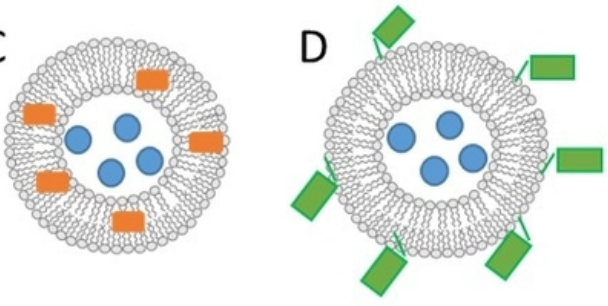

E

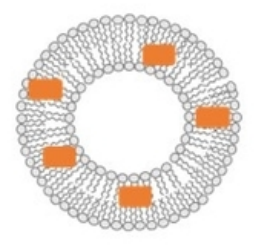

F

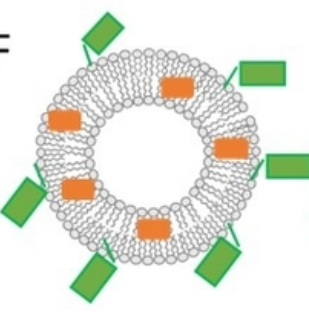

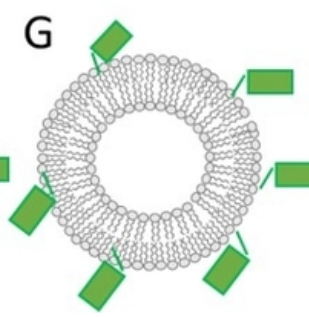

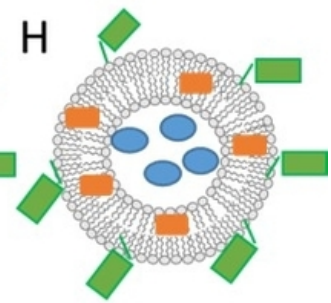

The schematic showing 'multifaceted nature of the liposomes' [105]. Total 8 fundamental ways to take structural advantage of liposomes as a carrier for different molecules (represented in blue, orange and green). (a) Empty liposomes (b) encapsulation in the hydrophilic core, (c) co-encapsulation in hydrophilic core and lipophilic bilayer, (d) encapsulation in the hydrophilic core and loading on the liposome surface, (e) encapsulation in the bilayer, (f) encapsulation in the bilayer and loading on the liposome surface, (g) loading on the liposome surface, $(h)$ encapsulation in the hydrophilic core as well as lipophilic bilayer and loading on the liposome surface.

$71 \times 34 \mathrm{~mm}(300 \times 300 \mathrm{DPI})$ 